Research article Open Access

\title{
Cardiovascular disease in patients with rheumatoid arthritis: results from the QUEST-RA study
}

Antonio Naranjo1, Tuulikki Sokka², Miguel A Descalzo ${ }^{3}$, Jaime Calvo-Alén ${ }^{4}$, Kim Hørslev-Petersen ${ }^{5}$, Reijo K Luukkainen6, Bernard Combe7, Gerd R Burmester8, Joe Devlin², Gianfranco Ferraccioli10, Alessia Morelli10, Monique Hoekstra ${ }^{11}$, Maria Majdan ${ }^{12}$, Stefan Sadkiewicz ${ }^{13}$, Miguel Belmonte ${ }^{14}$, Ann-Carin Holmqvist ${ }^{15}$, Ernest Choy ${ }^{16}$, Recep Tunc ${ }^{17}$, Aleksander Dimic ${ }^{18}$, Martin Bergman ${ }^{19}$, Sergio Toloza 20 , Theodore Pincus ${ }^{21}$ for the QUEST-RA Group

\author{
${ }^{1}$ Hospital de Gran Canaria Dr. Negrin, University of Las Palmas de Gran Canaria, Barranco de la Ballena s/n 35011, Spain \\ 2Jyväskylä Central Hospital, Jyväskylä, and Medcare Oy, Äänekoski, Finland; Jyväskylä Central Hospital, Keskussairaalantie 19, 40620 Jyväskylä, \\ Finland \\ ${ }^{3}$ Research Unit, Spanish Foundation of Rheumatology, C/Marqués de Duero, 5, 1ํ, 28001, Madrid, Spain \\ ${ }^{4}$ Hospital Sierrallana, Torrelavega, $B^{\circ}$. de Ganzo, s/n 39300, Spain \\ 5King Christian the Xth Hospital, Toldbodgade 3, 6300 Gråsten, Denmark \\ 6Satakunta Central Hospital, Rauman aluesairaala, Steniuksenkatu 2, 26100 Rauma, Finland \\ 7Hôpital Lapeyronie, 371, avenue du Doyen Gaston Giraud 34295 Montpellier Cedex 5, France \\ ${ }^{8}$ Charité - University Medicine Berlin, Chariteplatz 1, 10117 Berlin, Germany \\ 9Waterford Regional Hospital, Dunmore Road, Waterford, Co Waterford, Ireland \\ ${ }^{10}$ Catholic University of Sacred Heart, Largo F. Vito, $1-00168$, Rome, Italy \\ ${ }_{11}$ Medisch Spectrum Twente, Haaksbergerstraat 55, 7513 ER, Enschede, The Netherlands \\ 12Medical University of Lublin, al. Rac3awickie 1, 20-095, Lublin, Poland \\ ${ }^{13}$ Szpital Wojewodzki im. Jana Biziela, UI. Kornela Ujejskiego 65, 85-104 Bydgoszcz, Poland \\ ${ }^{14}$ Hospital General de Castellón, Avenida Benicasim S/N 12004 Castellón, Spain \\ ${ }^{15}$ Hudiksvall Medical Clinic, 82481 Hudiksvall, Sweden \\ ${ }^{16}$ Kings College Hospital, Strand, London WC2R 2LS UK \\ ${ }_{17}$ Meram Medical Faculty, Selcuk University, Konya 42090, Turkey \\ ${ }^{18}$ Rheumatology Institut, Srpskih Junaka 2, 18205 Niška Banja, Serbia \\ ${ }^{19}$ Taylor Hospital, 175 East Chester Pike, Ridley Park, Pennsylvania, PA 19078USA \\ ${ }^{20}$ Hospital San Juan Bautista, Avenida Illia 200, K4700ABO, Catamarca, Argentina \\ ${ }^{21}$ New York University Hospital for Joint Diseases, 301 East 17th Street, New York, New York 10003, USA
}

Corresponding author: Antonio Naranjo, anarher@gobiernodecanarias.org

Received: 1 Apr 2007 Revisions requested: 18 May 2007 Revisions received: 15 Nov 2007 Accepted: 6 Mar 2008 Published: 6 Mar 2008

Arthritis Research \& Therapy 2008, 10:R30 (doi:10.1186/ar2383)

This article is online at: http://arthritis-research.com/content/10/2/R30

(c) 2008 Naranjo et al.; licensee BioMed Central Ltd.

This is an open access article distributed under the terms of the Creative Commons Attribution License (http://creativecommons.org/licenses/by/2.0), which permits unrestricted use, distribution, and reproduction in any medium, provided the original work is properly cited.

\begin{abstract}
Introduction We analyzed the prevalence of cardiovascular (CV) disease in patients with rheumatoid arthritis (RA) and its association with traditional $\mathrm{CV}$ risk factors, clinical features of $\mathrm{RA}$, and the use of disease-modifying antirheumatic drugs (DMARDs) in a multinational cross-sectional cohort of nonselected consecutive outpatients with RA (The Questionnaires in Standard Monitoring of Patients with Rheumatoid Arthritis Program, or QUEST-RA) who were receiving regular clinical care.
\end{abstract}

\begin{abstract}
Methods The study involved a clinical assessment by a rheumatologist and a self-report questionnaire by patients. The clinical assessment included a review of clinical features of RA and exposure to DMARDs over the course of RA. Comorbidities were recorded; CV morbidity included myocardial infarction, angina, coronary disease, coronary bypass surgery, and stroke. Traditional risk factors recorded were hypertension, hyperlipidemia, diabetes mellitus, smoking, physical inactivity, and body mass index. Unadjusted and adjusted hazard ratios (HRs) (95\% confidence interval [Cl]) for CV morbidity were calculated using Cox proportional hazard regression models.
\end{abstract}

$\mathrm{BMI}=$ body mass index; $\mathrm{Cl}=$ confidence interval; $\mathrm{CV}=$ cardiovascular; DMARD = disease-modifying antirheumatic drug; $\mathrm{HAQ}=\mathrm{Health}$ Assessment Questionnaire; HR = hazard ratio; MONICA = Multinational Monitoring of Trends and Determinants in Cardiovascular Disease; NSAID = nonsteroidal anti-inflammatory drug; QUEST-RA = Questionnaires in Standard Monitoring of Patients with Rheumatoid Arthritis; RA = rheumatoid arthritis; RF = rheumatoid factor; SD = standard deviation; TNF- $\alpha=$ tumor necrosis factor-alpha. 
Results Between January 2005 and October 2006, the QUEST-RA project included 4,363 patients from 48 sites in 15 countries; $78 \%$ were female, more than $90 \%$ were Caucasian, and the mean age was 57 years. The prevalence for lifetime CV events in the entire sample was $3.2 \%$ for myocardial infarction, $1.9 \%$ for stroke, and $9.3 \%$ for any CV event. The prevalence for CV risk factors was $32 \%$ for hypertension, $14 \%$ for hyperlipidemia, $8 \%$ for diabetes, $43 \%$ for ever-smoking, $73 \%$ for physical inactivity, and $18 \%$ for obesity. Traditional risk factors except obesity and physical inactivity were significantly associated with CV morbidity. There was an association between any $\mathrm{CV}$ event and age and male gender and between extra-articular disease and myocardial infarction. Prolonged exposure to methotrexate ( $\mathrm{HR} 0.85 ; 95 \% \mathrm{Cl} 0.81$ to 0.89 ), leflunomide (HR $0.59 ; 95 \% \mathrm{Cl} 0.43$ to 0.79 ), sulfasalazine (HR $0.92 ; 95 \% \mathrm{Cl} 0.87$ to 0.98 ), glucocorticoids (HR 0.95; $95 \% \mathrm{Cl}$ 0.92 to 0.98 ), and biologic agents (HR $0.42 ; 95 \% \mathrm{Cl} 0.21$ to $0.81 ; P<0.05)$ was associated with a reduction of the risk of CV morbidity; analyses were adjusted for traditional risk factors and countries.

Conclusion In conclusion, prolonged use of treatments such as methotrexate, sulfasalazine, leflunomide, glucocorticoids, and tumor necrosis factor-alpha blockers appears to be associated with a reduced risk of CV disease. In addition to traditional risk factors, extra-articular disease was associated with the occurrence of myocardial infarction in patients with RA.

\section{Introduction}

Rheumatoid arthritis (RA) is associated with increased mortality, which is predominantly due to accelerated coronary artery and cerebrovascular atherosclerosis [1], a phenomenon that occurs in established and early RA [2-5]. Cardiovascular (CV) events occur approximately a decade earlier in RA than in the general population [6], suggesting that RA, similarly to diabetes mellitus, is an independent risk factor for premature ischemic heart disease $[7,8]$.

The use of methotrexate is associated with a significantly lower risk for $\mathrm{CV}$ events in RA patients compared with patients who had never used disease-modifying antirheumatic drugs (DMARDs) [9]. Suissa and colleagues [10] found a negative association between the rate of myocardial infarction and the current use of any DMARD in a case control study. A study from Sweden [11] suggested that the risk for developing first CV events in RA was lower in patients who were treated with tumor necrosis factor-alpha (TNF- $\alpha$ ) blockers. Our objective was to analyze the prevalence of $\mathrm{CV}$ morbidity in a large international sample of RA patients, its association with traditional $\mathrm{CV}$ risk factors, clinical features of RA, and with the use of DMARDs.

\section{Materials and methods}

QUEST-RA is short for Questionnaires in Standard Monitoring of Patients with Rheumatoid Arthritis. It is an international effort to perform an identical cross-sectional review of 100 nonselected consecutive outpatients with RA in three or more rheumatology clinics in several countries [12]. Countries that joined QUEST-RA by June 2006 were Denmark, Finland, France, Germany, Ireland, Italy, the Netherlands, Poland, Serbia, Spain, Sweden, Turkey, the UK, the USA, and Argentina. Approval for the study was obtained from local internal review boards or ethics committees, and patients signed an informed consent form.

\section{Clinical evaluation}

Patients were assessed according to a standard protocol to evaluate rheumatoid arthritis (SPERA) [13]. The rheumatolo- gists performed a clinical assessment including swollen and tender joint counts. Information concerning extra-articular features and comorbidities, including CV events, was established by a record review, a detailed clinical examination, and asking the patient at the time of the visit. The use of all DMARDs, including dates of start and discontinuation of each DMARD, was recorded. The most recent rheumatoid factor (RF) values were collected; RF was considered positive or negative according to the local reference values any time over the course of the disease. No training as to how to collect data or to perform joint counts was provided, and the study was intended to reflect routine clinical practice. All patients had fulfilled the American College of Rheumatology 1987 criteria for the classification of RA during the course of the disease [14].

The presence of subcutaneous nodules, lung disease (nodules, fibrosis, or pleuritis), Felty syndrome, vasculitis, pericarditis, and scleritis was counted for extra-articular disease. CV events included myocardial infarction, angina, coronary disease, coronary bypass surgery, and stroke. Dates of these events were recorded. These data were based on participating rheumatologists' reports of $\mathrm{CV}$ events on their patients and no other confirmation was required. The presence of hyperlipidemia, diabetes mellitus, and hypertension was recorded. No type specifications for hyperlipidemia or diabetes mellitus were made.

\section{Patient self-report}

The patients completed an expanded self-report health questionnaire that was first translated to each language; the study is explained elsewhere in more detail [12]. The questionnaire included the Health Assessment Questionnaire (HAQ) [15], years of education, height and weight for body mass index (BMI), and lifestyle choices such as smoking and frequency of physical exercise. Smokers were classified as 'nonsmokers' and 'ever-smokers', including 'current smokers'. Obesity was defined as BMl of greater than 30. 'Physical inactivity' included patient responses 'no exercise' or ' 1 to 2 times a month' versus exercises 'regular exercise one or more times a week'. 


\section{Statistical analyses}

Data are presented as means with standard deviations (SDs) and percentages with $95 \%$ confidence intervals (Cls). The Student $t$ test and chi-square test were used for comparison between groups.

The prevalence of CV events was calculated including all patients in the cohort who reported to have had a CV event. Patients with a CV event before the diagnosis of RA were excluded from the risk factor analyses. Time-to-event was calculated from the date of diagnosis of RA; patients with no CV event were censored at the date of evaluation. Univariate Cox proportional hazard regression models were computed to estimate the risk of any $\mathrm{CV}$ event including each of the traditional CV risk factors and disease characteristics as independent variables in separate models. Second, multivariate Cox proportional hazard regression models were computed to estimate the risk of all $\mathrm{CV}$ events, myocardial infarction, and stroke. Variables that were included in these models were age, gender, presence of RF, extra-articular disease, hypertension, hyperlipidemia, diabetes, smoking, obesity, physical inactivity, and country. Multivariate analyses were performed including all patients who had a CV event after a diagnosis of RA and separately for 'high' and 'low' CV prevalence countries (that is, countries above and below the median, respectively).
Time of exposure to each DMARD was calculated as the time (in years) that elapsed between the date of start of a DMARD and the date of discontinuation, CV event, or date of evaluation, which ever happened first. Each DMARD was analyzed independently in a Cox regression model, first unadjusted and then adjusted for age, gender, disease activity/severity (DAS 28 [disease activity score using 28 joint counts] and $\mathrm{HAQ}$ ), RA characteristics (RF positivity and presence of extra-articular manifestations), and the presence of traditional CV risk factors (hypertension, hyperlipidemia, diabetes, smoking, and obesity).

\section{Results \\ Patients}

Data collection began in January 2005, and in October 2006 the QUEST-RA project included 4,363 patients at 48 sites in 15 countries. Concerning demographic variables, this cohort represents a typical RA population: $78 \%$ of patients were female, 90\% were Caucasian, the mean (SD) age was 57 (14) years, the mean disease duration was 11 (9) years, and the mean duration of education was 10 (4) years. Overall, 74\% of patients had positive RF, ranging from $61 \%$ in Germany to 90\% in Argentina. Extra-articular disease was present in $24 \%$ of patients, ranging from less than $15 \%$ in Italy and the Netherlands to $34 \%$ in Denmark (Table 1).

Table 1

Patient characteristics in the QUEST-RA study per country

\begin{tabular}{|c|c|c|c|c|c|c|c|c|c|}
\hline Country & $\begin{array}{l}\text { Number of } \\
\text { sites }\end{array}$ & $\begin{array}{l}\text { Number of } \\
\text { patients }\end{array}$ & $\underset{\text { (mean) }}{\text { Age in years }}$ & Female (\%) & $\begin{array}{c}\text { Years of } \\
\text { education (mean) }\end{array}$ & $\begin{array}{l}\text { Disease duration } \\
\text { in years (mean) }\end{array}$ & RF-positive (\%) & $\begin{array}{l}\text { Extra-articular } \\
\text { disease }^{\mathrm{a}}(\%)\end{array}$ & $\begin{array}{l}\text { Cardiovascular } \\
\text { events (all)b }(\%)\end{array}$ \\
\hline Denmark & 3 & 301 & 58 & 76 & 11 & 12 & 74 & 34 & 9.97 \\
\hline Finland & 3 & 304 & 59 & 72 & 10 & 13 & 75 & 18 & 11.18 \\
\hline France & 4 & 389 & 55 & 78 & 11 & 13 & 75 & 21 & 3.60 \\
\hline Germany & 3 & 225 & 59 & 84 & 10 & 13 & 61 & 36 & 17.78 \\
\hline Ireland & 3 & 225 & 57 & 64 & 11 & 11 & 81 & 30 & 6.67 \\
\hline Italy & 4 & 336 & 61 & 78 & 8 & 10 & 73 & 13 & 8.93 \\
\hline Netherlands & 3 & 317 & 59 & 68 & 11 & 9 & 69 & 13 & 9.46 \\
\hline Poland & 7 & 642 & 53 & 86 & 12 & 11 & 71 & 33 & 11.84 \\
\hline Spain & 3 & 301 & 60 & 74 & 10 & 11 & 71 & 23 & 9.97 \\
\hline Sweden & 3 & 248 & 59 & 72 & 10 & 12 & 82 & 23 & 8.47 \\
\hline UK & 3 & 126 & 60 & 78 & 12 & 15 & 84 & 30 & 10.32 \\
\hline Turkey & 3 & 309 & 52 & 85 & 7 & 11 & 69 & 18 & 6.80 \\
\hline Serbia & 1 & 100 & 59 & 88 & 8 & 10 & 71 & 23 & 9.00 \\
\hline USA & 3 & 294 & 57 & 72 & 14 & 9 & 70 & 24 & 11.56 \\
\hline Argentina & 2 & 246 & 51 & 90 & 9 & 10 & 90 & 26 & 3.66 \\
\hline Total & 48 & 4,363 & $57 \pm 1$ & 78 & $10 \pm 4$ & $11 \pm 9$ & 73.7 & 24.3 & 9.31 \\
\hline
\end{tabular}

alncludes nodules, pulmonal fibrosis, pericarditis, vasculitis, Felty syndrome, and scleritis. bMyocardial infarction, angina, coronary heart disease, coronary bypass surgery, or stroke. QUEST-RA, Questionnaires in Standard Monitoring of Patients with Rheumatoid Arthritis; RF, rheumatoid factor. 


\section{Cardiovascular morbidity}

The overall prevalence of CV morbidity (myocardial infarction, angina, coronary disease, or stroke) was 9.3\%, with considerable variation between countries (less than 5\% in Argentina and France and greater than $10 \%$ in Finland, Germany, Poland, the UK, and the USA) (Table 1). CV events were more prevalent in men than in women (Table 2). The overall prevalence for the whole cohort of lifetime myocardial infarction was $3.2 \%$, and the prevalence for stroke was $1.9 \%$.

\section{Traditional cardiovascular risk factors}

The prevalence of CV risk factors was 33\% for hypertension, $14 \%$ for hyperlipidemia, $8 \%$ for diabetes, $43 \%$ for smoking ever, $72 \%$ for physical inactivity, and $18 \%$ for obesity. Diabetes was more frequent in men (10\%) than in women $(7 \%)$ (Table 2). More men than women had ever smoked (68\% versus $37 \% ; P=0.0001$ ) or were current smokers (26\% versus $15 \% ; P=0.0001)$.

In a univariate Cox regression analysis, extra-articular disease was statistically significantly associated with CV morbidity (Table 3). Among traditional CV risk factors, age, gender, hypertension, hyperlipidemia, ever-smoking, and diabetes showed a statistically significant association with CV events.

In a multivariate Cox regression analysis, older age, male gender, hypertension, hyperlipidemia, and ever-smoking were independently associated with occurrence of $\mathrm{CV}$ events (Table 4). Extra-articular RA (hazard ratio [HR] 2.26; 95\% Cl
1.29 to 3.97), hyperlipidemia ( $\mathrm{HR} 3.51 ; 95 \% \mathrm{Cl} 1.98$ to 6.21 ), and ever-smoking (HR 3.20; 95\% Cl 1.74 to 5.90) were all associated with myocardial infarction although association of extra-articular disease was not statistically significant in 'low prevalence' (of CV disease) countries (Table 4). Hypertension (HR 2.81; 95\% Cl 1.49 to 5.30) and diabetes (HR 2.23; 95\% Cl 1.12 to 4.44) were associated with stroke; associations were statistically significant for hypertension in 'high prevalence' countries and for diabetes in 'low prevalence' countries (Table 4).

\section{Disease-modifying antirheumatic drugs and glucocorticoids}

Patients who had hypertension were treated less frequently with methotrexate and biologic agents compared with patients who had no hypertension, but the former were treated more frequently with leflunomide and glucocorticoids (data not shown). Table 5 shows the HR for the occurrence of $\mathrm{CV}$ events by year of exposure to each DMARD, when adjusted to age, gender, disease activity, and traditional risk factors. One year of methotrexate use was associated with $15 \%, 18 \%$, and $11 \%$ decreases of risk for all CV events, myocardial infarction, and stroke, respectively. Leflunomide was also associated with a reduced risk of $\mathrm{CV}$ events, and glucocorticoids and sulfasalazine were associated with a small but significantly reduced risk of all CV events. A lower risk for all CV events and myocardial infarction was also associated with a longer exposition-duration to TNF- $\alpha$ blockers (HR $0.42 ; 95 \% \mathrm{Cl} 0.21$ to $0.81 ; P<0.05)$.

Table 2

Cardiovascular morbidity and risk factors in the QUEST-RA study by gender

\begin{tabular}{|c|c|c|c|c|}
\hline & \multicolumn{2}{|c|}{ Male } & \multicolumn{2}{|c|}{ Female } \\
\hline & Mean/\% & $95 \% \mathrm{Cl}$ & Mean/\% & $95 \% \mathrm{Cl}$ \\
\hline Myocardial infarction ${ }^{\mathrm{a}}$ & 8 & $6-10$ & 2 & $1-2$ \\
\hline Stroke ${ }^{b}$ & 3 & $2-4$ & 2 & $1-2$ \\
\hline Cardiovascular (all)a,c & 16 & $14-18$ & 7 & $7-8$ \\
\hline Age in years ${ }^{a}$ & 58.9 & $58.1-59.7$ & 56.3 & $55.8-56.7$ \\
\hline Disease duration in years ${ }^{a}$ & 8.8 & $8.2-9.4$ & 10.0 & $9.7-10.3$ \\
\hline Rheumatoid factor-positive & 74 & $71-76$ & 72 & $70-73$ \\
\hline Hypertension & 31 & $28-34$ & 32 & $31-34$ \\
\hline Hyperlipidemia & 13 & $11-16$ & 14 & $13-15$ \\
\hline Diabetes mellitus ${ }^{b}$ & 10 & $8-12$ & 7 & $6-8$ \\
\hline Smoking evera & 68 & $65-71$ & 37 & $35-38$ \\
\hline Smoking now ${ }^{a}$ & 26 & $23-29$ & 15 & $14-17$ \\
\hline Body mass index $\geq 30^{a}$ & 13 & $11-15$ & 19 & $18-20$ \\
\hline Physical inactivityd & 68 & $65-71$ & 73 & $72-75$ \\
\hline
\end{tabular}

a $P<0.001 .{ }^{b} P<0.05$. cMyocardial infarct, angina, coronary heart disease, bypass, or stroke. ${ }^{\mathrm{d}} P<0.01 . \mathrm{Cl}$, confidence interval; QUEST-RA, Questionnaires in Standard Monitoring of Patients with Rheumatoid Arthritis. 
Table 3

\begin{tabular}{|c|c|c|c|c|c|}
\hline \multicolumn{6}{|c|}{ Cardiovascular morbidity (percentage of patients) } \\
\hline & No & Yes & Hazard ratio & $95 \% \mathrm{Cl}$ & $P$ value \\
\hline \multicolumn{6}{|l|}{ Rheumatoid variables } \\
\hline Rheumatoid factor & 71.7 & 77.0 & 1.02 & $0.76-1.37$ & 0.881 \\
\hline Extra-articular disease ${ }^{a}$ & 23.0 & 43.3 & 1.52 & $1.19-1.95$ & 0.001 \\
\hline \multicolumn{6}{|l|}{ Traditional risk factors } \\
\hline Age in years (mean) & 55.8 & 66.4 & 1.05 & $1.04-1.06$ & 0.000 \\
\hline Gender (female) & 79.4 & 64.0 & 0.42 & $0.33-0.54$ & 0.000 \\
\hline Hypertension & 28.7 & 62.9 & 2.97 & $2.31-3.83$ & 0.000 \\
\hline Hyperlipidemia & 11.3 & 34.0 & 3.19 & $2.47-4.13$ & 0.000 \\
\hline Diabetes & 6.9 & 15.8 & 2.09 & $1.50-2.92$ & 0.000 \\
\hline Smoking ever & 42.6 & 51.2 & 1.60 & $1.25-2.04$ & 0.000 \\
\hline Smoking now & 18.3 & 11.8 & 0.80 & $0.55-1.18$ & 0.260 \\
\hline Obesity & 17.5 & 18.3 & 1.34 & $0.96-1.86$ & 0.082 \\
\hline Physical inactivity & 71.9 & 73.5 & 1.00 & $0.75-1.33$ & 0.993 \\
\hline
\end{tabular}

alncludes nodules, pulmonal fibrosis, pericarditis, vasculitis, Felty syndrome, and scleritis. Cl, confidence interval; QUEST-RA, Questionnaires in Standard Monitoring of Patients with Rheumatoid Arthritis.

\section{Discussion}

This study provides further support to the concept that a prolonged use of DMARDs, glucocorticoids, and TNF- $\alpha$ blockers is associated with a reduced risk of $\mathrm{CV}$ events. Furthermore, extra-articular RA was found to be associated with the occurrence of myocardial infarction, and the role of traditional risk factors for $\mathrm{CV}$ morbidity was confirmed.

\section{Incidence and prevalence of cardiovascular disease in rheumatoid arthritis}

Patients with RA are $30 \%$ to $60 \%$ more likely to suffer a CV event compared with the general population [16,17], especially myocardial infarction [18-20], whereas the incidence and prevalence of stroke generally have been reported to be similar in RA as in the general population or in patients with osteoarthritis $[18,20]$. Only one study found higher prevalence of stroke in RA than in controls [16]. We found a lower prevalence of stroke compared with other cross-sectional studies $[16,18]$, although comparative data for the reference from general populations were not available in our study.

The crude prevalence of CV events differed between countries (Table 1). Results in the present study, to some extent, are similar to those in the World Health Organization MONICA (Multinational Monitoring of Trends and Determinants in Cardiovascular Disease) project, in which the highest rates of myocardial infarction were seen in Finland, Poland, and the UK and lowest in the Mediterranean countries [21], possibly related to the Mediterranean diet and lifestyle, which are associated with a greater than 50\% decrease of all-cause and cause-specific mortality in the general population [22]. However, our data are not directly comparable to the MONICA study, in which participants were less than 65 years old, whereas the QUEST-RA patients are predominantly older females.

\section{Traditional risk factors for cardiovascular disease}

In our study, the frequency of CV events was double in men compared with women (four times for myocardial infarction) and does not provide any surprises compared with observations in the general population [21]. In univariate analyses, all traditional CV risk factors, except obesity and physical inactivity, were associated with CV morbidity, and in multivariate models, hypertension, hyperlipidemia, diabetes, and eversmoking remained independent risk factors. Thus, our results confirm the role of traditional risk factors concerning $\mathrm{CV}$ morbidity in patients with RA. However, it needs to be recognized that our analyses are restricted to people who survived following a CV event due to the cross-sectional nature of the study and some of the predictors being identified may be predictors of survival following a CV event rather than the occurrence of the event. Furthermore, we did not collect data on family history of CV disease, which appears a significant risk factor for CV morbidity also in patients with RA [23]. 
Table 4

Multivariate model for cardiovascular morbidity in the QUEST-RA study

\begin{tabular}{lccc}
\hline & & \multicolumn{2}{c}{$\begin{array}{c}\text { Cardiovascular events (all)a hazard ratio (95\% Cl) } \\
\text { Countries with high prevalence }\end{array}$} \\
& All countries & $1.05(1.03-1.07)^{\mathrm{b}}$ & $1.04(1.01-1.06)^{\mathrm{c}}$ \\
\hline Age & $1.04(1.03-1.06)^{\mathrm{b}}$ & $0.45(0.31-0.66)^{\mathrm{b}}$ & $0.55(0.32-0.94)^{\mathrm{c}}$ \\
Gender (female) & $0.49(0.36-0.66)^{\mathrm{b}}$ & $0.95(0.64-1.41)$ & $0.90(0.46-1.73)$ \\
Rheumatoid factor & $0.95(0.68-1.33)$ & $1.28(0.92-1.80)$ & $1.60(0.91-2.84)$ \\
Extra-articular disease & $1.33(1.00-1.78)$ & $1.85(1.29-2.64)^{\mathrm{c}}$ & $2.23(1.28-3.90)^{\mathrm{c}}$ \\
Hypertension & $1.95(1.44-2.63)^{\mathrm{b}}$ & $2.16(1.50-3.10)^{\mathrm{b}}$ & $3.24(1.86-5.65)^{\mathrm{b}}$ \\
Hyperlipidemia & $2.41(1.78-3.27)^{\mathrm{b}}$ & $1.05(0.65-1.69)$ & $2.20(1.18-4.09)^{\mathrm{c}}$ \\
Diabetes & $1.34(0.92-1.96)$ & $1.46(1.01-2.11)^{\mathrm{d}}$ & $1.88(1.10-3.22)^{\mathrm{c}}$ \\
Ever-smoking & $1.56(1.16-2.12)^{\mathrm{c}}$ & $1.52(1.01-2.27)^{\mathrm{d}}$ & $0.57(0.25-1.28)$ \\
Obesity & $1.16(0.81-1.66)$ & $1.11(0.75-1.65)$ & $0.61(0.33-1.10)$
\end{tabular}

Myocardial infarction hazard ratio $(95 \% \mathrm{Cl})$

\begin{tabular}{|c|c|c|c|}
\hline & All countries & Countries with high prevalence & Countries with low prevalence \\
\hline Age & $1.05(1.02-1.08)^{\mathrm{c}}$ & $1.04(1.01-1.08)^{c}$ & $1.06(1.00-1.13)^{c}$ \\
\hline Gender (female) & $0.46(0.27-0.80)^{c}$ & $0.55(0.29-1.06)$ & $0.37(0.13-1.04)$ \\
\hline Rheumatoid factor & $0.68(0.36-1.31)$ & $0.68(0.31-1.48)$ & $0.82(0.23-2.91)$ \\
\hline Extra-articular disease & $2.26(1.29-3.97)^{c}$ & $2.26(1.17-4.37)^{c}$ & $2.13(0.71-6.35)$ \\
\hline Hypertension & $1.45(0.83-2.53)$ & $1.10(0.57-2.15)$ & $2.19(0.72-6.71)$ \\
\hline Hyperlipidemia & $3.51(1.98-6.21)^{\mathrm{b}}$ & $3.51(1.80-6.84)^{\mathrm{b}}$ & $4.34(1.41-13.33)^{c}$ \\
\hline Diabetes & $1.18(0.59-2.38)$ & $1.27(0.56-2.90)$ & $1.01(0.24-4.29)$ \\
\hline Ever-smoking & $3.20(1.74-5.90)^{b}$ & $2.47(1.22-4.99)^{\mathrm{c}}$ & $12.14(2.50-59.05)^{c}$ \\
\hline Obesity & $0.74(0.34-1.62)$ & $0.59(0.22-1.57)$ & $1.36(0.37-5.01)$ \\
\hline \multirow[t]{3}{*}{ Physical inactivity } & $0.88(0.46-1.65)$ & $0.96(0.45-2.07)$ & $0.87(0.24-3.12)$ \\
\hline & \multicolumn{3}{|c|}{ Stroke hazard ratio $(95 \% \mathrm{Cl})$} \\
\hline & All countries & Countries with high prevalence & Countries with low prevalence \\
\hline Age & $1.02(0.99-1.05)$ & $1.03(1.00-1.06)$ & $0.99(0.93-1.05)$ \\
\hline Gender (female) & $0.59(0.31-1.12)$ & $0.66(0.31-1.42)$ & $0.37(0.10-1.39)$ \\
\hline Rheumatoid factor & $0.95(0.45-2.00)$ & $0.88(0.38-2.06)$ & $2.67(0.40-17.71)$ \\
\hline Extra-articular disease & $1.41(0.77-2.58)$ & $1.43(0.69-2.94)$ & $1.31(0.40-4.30)$ \\
\hline Hypertension & $2.81(1.49-5.30)^{c}$ & $2.95(1.43-6.11)^{\mathrm{c}}$ & $2.37(0.61-9.20)$ \\
\hline Hyperlipidemia & $1.18(0.60-2.31)$ & $0.69(0.27-1.76)$ & $3.69(1.16-11.78)^{\mathrm{c}}$ \\
\hline Diabetes & $2.23(1.12-4.44)^{d}$ & $1.70(0.71-4.07)$ & $4.63(1.31-16.40)^{c}$ \\
\hline Ever-smoking & $1.66(0.89-3.09)$ & $1.74(0.82-3.69)$ & $1.31(0.37-4.63)$ \\
\hline Obesity & $0.72(0.31-1.68)$ & $0.77(0.28-2.08)$ & $0.56(0.11-2.69)$ \\
\hline Physical inactivity & $1.01(0.50-2.03)$ & $1.30(0.59-2.87)$ & $0.52(0.13-2.09)$ \\
\hline
\end{tabular}

High and low values of each cardiovascular event are based on the median. All variables are included simultaneously in the model, adjusted for country. aMyocardial infarct, angina, coronary heart disease, bypass, or stroke. bP $<0.001 .{ }^{\circ} P<0.01$. d $P<0.05$. Cl, confidence interval; QUESTRA, Questionnaires in Standard Monitoring of Patients with Rheumatoid Arthritis. 
Years of exposure to disease-modifying antirheumatic drugs and cardiovascular morbidity in patients with rheumatoid arthritis in the QUEST-RA study

\begin{tabular}{|c|c|c|c|c|c|}
\hline & \multirow[t]{2}{*}{$\mathrm{HR}^{\mathrm{a}}(95 \% \mathrm{Cl}) \mathrm{CV}$ all types } & \multirow[t]{2}{*}{$\mathrm{HR}^{\mathrm{b}}(95 \% \mathrm{Cl}) \mathrm{CV}$ all types } & \multicolumn{3}{|c|}{$\mathrm{HRc}(95 \% \mathrm{Cl})$} \\
\hline & & & CV all types & Myocardial infarction & Stroke \\
\hline Methotrexate & $0.82(0.79-0.86)^{d}$ & $0.84(0.80-0.87)^{d}$ & $0.85(0.81-0.89)^{d}$ & $0.82(0.74-0.91)^{d}$ & $0.89(0.82-0.98)^{\mathrm{e}}$ \\
\hline Glucocorticoids & $0.94(0.92-0.97)^{d}$ & $0.95(0.93-0.97)^{d}$ & $0.95(0.92-0.98)^{d}$ & $0.96(0.91-1.00)$ & $0.98(0.93-1.03)$ \\
\hline Antimalarials & $0.94(0.91-0.98)^{f}$ & $0.95(0.91-0.99)^{f}$ & $0.98(0.94-1.02)$ & $0.94(0.85-1.03)$ & $0.87(0.76-1.01)$ \\
\hline Sulfasalazine & $0.91(0.87-0.96)^{d}$ & $0.92(0.88-0.97)^{f}$ & $0.92(0.87-0.98)^{f}$ & $0.82(0.69-0.98) \mathrm{e}$ & $0.90(0.79-1.03)$ \\
\hline Gold & $0.96(0.92-1.00)^{\mathrm{e}}$ & $0.96(0.92-1.00) \mathrm{e}$ & $0.99(0.95-1.03)$ & $1.04(0.98-1.10)$ & $0.98(0.89-1.07)$ \\
\hline Leflunomide & $0.52(0.38-0.72)^{d}$ & $0.55(0.41-0.75)^{d}$ & $0.59(0.43-0.79)^{f}$ & $0.52(0.26-1.06)$ & $0.91(0.65-1.28)$ \\
\hline TNF- $\alpha$ blockers & $0.67(0.53-0.85)^{f}$ & $0.71(0.56-0.89)^{f}$ & $0.64(0.49-0.83)^{f}$ & $0.42(0.21-0.81) \mathrm{e}$ & $0.64(0.39-1.05)$ \\
\hline
\end{tabular}

Physical inactivity is common in the general population and a frequent consequence of arthritis. In the general population, the frequency of weekly physical activity of three or more times is associated with reduced CV morbidity [24]. In the present study, only $13 \%$ of patients exercised three or more times a week [25]. Physical inactivity (exercise frequency ' 1 to 2 times a month' and 'none') was not associated with CV disease in our analyses.

\section{Cardiovascular morbidity and rheumatoid arthritis- related risk factors}

$\mathrm{RA}$ is associated with premature and accelerated atherosclerosis $[16,26]$. Carotid artery ultrasound and coronary angiography have shown that atheromatosis is more frequent in RA than controls $[27,28]$ and is related to the extent of radiographic damage of joints, which, in turn, is indicative of sustained inflammation [29]. Moreover, multivessel coronary artery calcifications in RA are related to smoking and an elevated sedimentation rate [4]. An elevated C-reactive protein at baseline predicted $\mathrm{CV}$ mortality over the follow-up of 10 years in patients with inflammatory polyarthritis in general and particularly in RF-positive patients [30,31]. Some processes intrinsic to the pathogenesis of RA play important roles in CV damage and its clinical consequences: abnormal endothelial function [32], autoantibodies against oxidized low-density lipoprotein [33], and levels of serum mannose-binding leptin [34].

Van Halm and colleagues [9] found an association between CV disease and seropositive and erosive RA, and Turesson and colleagues $[8,35]$ between $\mathrm{CV}$ morbidity and mortality and extra-articular disease. The present study lends further support to the significant association between extra-articular disease and CV morbidity, and this observation underlines higher CV morbidity in severe RA.

\section{Antirheumatic drugs and cardiovascular disease}

Some of the medications used to treat RA might increase the risk for CV morbidity. The risk of myocardial infarction is increased in nonsteroidal anti-inflammatory drug (NSAID) and cyclooxygenase 2 inhibitor users, especially with rofecoxib [36,37].

Glucocorticoids might increase CV morbidity by promoting proatherosclerotic lipid profiles [38,39]. Two recent articles show an increased rate of CV events with long-term use of glucocorticoids [10,40]. However, Davis and colleagues [41] found no association between cumulative glucocorticoid exposure and CV events in RA patients followed for a median of 15 years, after adjusting for other $\mathrm{CV}$ risk factors and markers of RA activity. In the present study, long-term use of glucocorticoids was independently associated with a reduced risk of 'all' CV events (Table 5).

The use of methotrexate has been associated with a significantly lower risk for $\mathrm{CV}$ events in RA patients compared with patients who had never used DMARDs [9]. Long-term followup of RA patients has shown that the use of methotrexate is significantly associated with reduced overall and CV mortality [42].

Suissa and colleagues [10], in a case control study, found that the use of DMARDs was associated with a decreased rate of myocardial infarction. However, Solomon and colleagues [40], in a case control study, found a higher risk for CV events in patients who had received cyclosporine, azathioprine, or leflunomide. In our study, longer use of DMARDs such as methotrexate, leflunomide, and sulfasalazine was associated with a decreased risk of CV disease. The association remained statistically significant for myocardial infarction with methotrexate $(P<0.001)$ and sulfasalazine $(P<0.05)$, even when adjusted 
for disease severity and traditional risk factors such as smoking, which is a risk factor for both CV disease and RA [43]. In contrast, the use of antimalarials and intramuscular gold was not associated with a change of the risk of $\mathrm{CV}$ disease. In one report, atherogenic lipid profiles of RA patients improved after specific therapy for arthritis, primarily due to the increase of serum high-density lipoprotein cholesterol levels [44].

With respect to TNF- $\alpha$ blockers, infliximab may improve endothelial function in RA after 12 weeks of therapy [45], suggesting that inflammation is a mediator of endothelial dysfunction, although such beneficial effects do not appear to sustain for a long time $[46,47]$. A recent study suggested that the risk for developing first $\mathrm{CV}$ events in RA is lower in patients treated with TNF- $\alpha$ blockers [11]. However, that study did not control for most of the traditional risk factors for accelerated atherosclerosis. On the other hand, two case control studies showed no reduction of infarction rate in RA with TNF- $\alpha$ blockers $[10,41]$. Other recent reports from large databases show discordant results on CV disease incidence in TNF users versus nonusers [48-50]. In the present study, longer use of TNF- $\alpha$ blockers was associated with a reduced risk of CV disease although limited availability of biologics might interfere with the results. Furthermore, patients with suspected CV disease may not be prescribed biologic agents.

Several limitations are to be recognized. First, QUEST-RA is a cross-sectional study with a possible left censorship concerning CV events. Many patients may have experienced a fatal CV event and, therefore, could not be included in this study. Second, all data are based on participating rheumatologists' reports and no verification of data was performed. Therefore, it is possible that some data could be missed. Third, data on the longitudinal use of NSAIDs or cyclooxygenase 2 inhibitors were not collected. Fourth, the extent of radiographic erosions (representing cumulative disease activity) was not analyzed in the present study. Despite limitations, QUEST-RA is a unique program that has succeeded to date in collecting data on clinical RA patients according to an identical protocol in various locales in various countries and various cultures and provides data that are not available from any other resources at this time.

\section{Conclusion}

Our study provides further support of the influence of both traditional and RA-specific risk factors in the development of CV events, especially myocardial infarction. As assessed by this study, the risk was lower with the prolonged use of methotrexate, sulfasalazine, glucocorticoids, leflunomide, and TNF- $\alpha$ blockers.

\section{Competing interests}

The authors declare that they have no competing interests.

\section{Authors' contributions}

The QUEST-RA study was designed and conducted by TS and TP. All authors participated in data collection concerning their clinical patients. Analyses for the present report were designed and coordinated by AN and performed by MAD. AN drafted the manuscript with the help of TS. All authors read and approved the final manuscript.

\section{Acknowledgements}

Abbott Laboratories (Abbott Park, IL, USA) provided financial support for this study.

The QUEST-RA Group is composed of the following members: Denmark: Merete Lund Hetland and Louise Linde, Copenhagen University Hospital at Hvidovre, Hvidovre; Kim Hørslev-Petersen, King Christian the Xth Hospital, Gråsten; and Troels Mørk Hansen and Lene Surland Knudsen, Copenhagen University Hospital at Herlev, Herlev; Finland: Heidi Mäkinen, Jyväskylä Central Hospital, Jyväskylä; Kai Immonen, Sinikka Forsberg, and Jukka Lähteenmäki, North Karelia Central Hospital, Joensuu; and Reijo Luukkainen, Satakunta Central Hospital, Rauma; France: Laure Gossec and Maxime Dougados, University René Descartes, Hôpital Cochin, Paris; Jean Francis Maillefert, Dijon University Hospital, University of Burgundy, Dijon; Bernard Combe, Hôpital Lapeyronie, Montpellier; and Jean Sibilia, Hôpital Hautepierre, Strasbourg; Germany: Gertraud Herborn and Rolf Rau, Evangelisches Fachkrankenhaus, Ratingen; Rieke Alten and Christof Pohl, Schlosspark-Klinik, Berlin; and Gerd R Burmester, Bettina Marsmann, Charité - University Medicine Berlin, Berlin; Ireland: Barry Bresnihan, St. Vincent University Hospital, Dublin; Patricia Minnock, Our Lady's Hospice, Dublin; Eithne Murphy, Claire Sheehy, and Edel Quirke, Connolly Hospital, Dublin; and Joe Devlin and Shafeeq Alraqi, Waterford Regional Hospital, Waterford; Italy: Massimiliano Cazzato and Stefano Bombardieri, Santa Chiara Hospital, Pisa; Gianfranco Ferraccioli and Alessia Morelli, Catholic University of Sacred Heart, Rome; Maurizio Cutolo, University of Genova, Genova; and Fausto Salaffi, Andrea Stancati, University of Ancona, Ancona; the Netherlands: Suzan MM Verstappen, and Johannes WG Jacobs, University Medical Center Utrecht, Utrecht; Margriet Huisman, Sint Franciscus Gasthuis Hospital, Rotterdam; and Monique Hoekstra, Medisch Spectrum Twente, Enschede; Poland: Stanislaw Sierakowski, Medical University in Bialystok, Bialystok; Maria Majdan, Medical University of Lublin, Lublin; Wojciech Romanowski, Poznan Rheumatology Center in Srem, Srem; Witold Tlustochowicz, Military Institute of Medicine, Warsaw; Danuta Kapolka, Silesian Hospital for Rheumatology and Rehabilitation in Ustroñ Ślaski, Ustroñ Ślaski; Stefan Sadkiewicz, Szpital Wojewodzki im. Jana Biziela, Bydgoszcz; and Danuta Zarowny-Wierzbinska, Wojewodzki Zespol Reumatologiczny im. dr Jadwigi Titz-Kosko, Sopot; Spain: Antonio Naranjo, Hospital de Gran Canaria Dr. Negrin, Las Palmas; Jaime Calvo-Alén, Hospital Sierrallana Ganzo, Torrelavega; Carlos Rodríguez-Lozano, Hospital de Gran Canaria Dr Negrín, Las Palmas; and Miguel Belmonte, Hospital General de Castellón, Castellón; Sweden: Eva Baecklund and Dan Henrohn, Uppsala University Hospital, Uppsala; Rolf Oding and Margareth Liveborn, Centrallasarettet, Västerås; and Ann-Carin Holmqvist, Hudiksvall Medical Clinic, Hudiksvall; the UK: Peter Taylor and Catherine McClinton, Charing Cross Hospital, London; Anthony Woolf and Ginny Chorghade, Royal Cornwall Hospital, Truro; and Ernest Choy and Stephen Kelly, Kings College Hospital, London; Turkey: Feride Gogus, Gazi Medical School, Ankara; Recep Tunc, Meram Medical Faculty, Konya; and Selda Celic, Cerrahpasa Medic Faculty, Istanbul; Serbia: Vlado Skakic, Aleksander Dimic, Jovan Nedovic, and Aleksandra Stankovic, Rheumatology Institut, Niska Banja; the USA: Theodore Pincus and Christopher Swearingen, Vander- 
bilt University, Nashville, TN; Yusuf Yazici, NYU Hospital for Joint Diseases, New York, NY; and Martin Bergman, Taylor Hospital, Ridley Park, PA; Argentina: Sergio Toloza, Santiago Aguero, Sergio Orellana Barrera, and Soledad Retamozo, Hospital San Juan Bautista, Catamarca, and Paula Alba, Cruz Lascano, Alejandra Babini, and Eduardo Albiero, Hospital of Cordoba, Cordoba; and study center: Tuulikki Sokka, Jyväskylä Central Hospital, Jyväskylä and Medcare Oy, Äänekoski, Finland, and Theodore Pincus, New York University Hospital for Joint Diseases, New York, NY, USA.

\section{References}

1. Kaplan MJ: Cardiovascular disease in rheumatoid arthritis. Curr Opin Rheumatol 2006, 18:289-297.

2. Goodson NJ, Wiles NJ, Lunt M, Barrett EM, Silman AJ, Symmons DP: Mortality in early inflammatory polyarthritis: cardiovascular mortality is increased in seropositive patients. Arthritis Rheum 2002, 46:2010-2019.

3. Wallberg-Jonsson S, Johansson H, Ohman ML, Rantapaa-Dahlqvist S: Extent of inflammation predicts cardiovascular disease and overall mortality in seropositive rheumatoid arthritis. A retrospective cohort study from disease onset. I Rheumatol 1999, 26:2562-2571.

4. Chung CP, Oeser A, Raggi P, Gebretsadik T, Shintani AK, Sokka $T$, Pincus T, Avalos I, Stein CM: Increased coronary-artery atherosclerosis in rheumatoid arthritis: relationship to disease duration and cardiovascular risk factors. Arthritis Rheum 2005, 52:3045-3053.

5. Turesson C, Jacobsson L, Bergström U: Extra-articular rheumatoid arthritis: prevalence and mortality. Rheumatology (Oxford) 1999, 38:668-674

6. Bacon PA, Stevens RJ, Carruthers DM, Young SP, Kitas GD: Accelerated atherogenesis in autoimmune rheumatic diseases. Autoimmun Rev 2002, 1:338-347.

7. del Rincon ID, Williams K, Stern MP, Freeman GL, Escalante A: High incidence of cardiovascular events in a rheumatoid arthritis cohort not explained by traditional cardiac risk factors. Arthritis Rheum 2001, 44:2737-2745.

8. Solomon DH, Goodson NJ, Katz JN, Weinblatt ME, Avorn J, Setoguchi S, Canning C, Schneeweiss S: Patterns of cardiovascular risk in rheumatoid arthritis. Ann Rheum Dis 2006, 65:1608-1612.

9. van Halm VP, Nurmohamed MT, Twisk JWR, Dijkmans BAC, Voskuyl $A E$ : Disease-modifying antirheumatic drugs are associated with a reduced risk for cardiovascular disease in patients with rheumatoid arthritis: a case control study. Arthritis Res Ther 2006, 8:R151.

10. Suissa $S$, Bernatsky $S$, Hudson M: Antirheumatic drug use and the risk of acute myocardial infarction. Arthritis Rheum 2006, 55:531-536.

11. Jacobsson LT, Turesson C, Gulfe A, Kapetanovic MC, Petersson IF, Saxne T, Geborek P: Treatment with tumor necrosis factor blockers is associated with a lower incidence of first cardiovascular events in patients with rheumatoid arthritis. J Rheumato/ 2005, 32:1213-1218.

12. Sokka T, Kautiainen $H$, Toloza $S$, Mäkinen $H$, Verstappen $S M$, Lund Hetland M, Naranjo A, Baecklund E, Herborn G, Rau R, Cazzato M, Gossec L, Skakic V, Gogus F, Sierakowski S, Bresnihan B, Taylor P, McClinton C, Pincus T, QUEST-RA Group: QUEST-RA: quantitative clinical assessment of patients with rheumatoid arthritis seen in standard rheumatology care in $\mathbf{1 5}$ countries. Ann Rheum Dis 2007, 66:1491-1496.

13. Sokka T: Rheumatoid arthritis databases. Rheum Dis Clin North Am 2004, 30:769-781.

14. Arnett FC, Edworthy SM, Bloch DA, McShane DJ, Fries JF, Cooper NS, Healey LA, Kaplan SR, Liang MH, Luthra HS, Medsger TA Jr, Mitchell DM, Neustadt DH, Pinals RS, Schaller JG, Sharp JT, Wilder RL, Hunder GG: The American Rheumatism Association 1987 revised criteria for the classification of rheumatoid arthritis. Arthritis Rheum 1988, 31:315-324.

15. Fries JF, Spitz P, Kraines RG, Holman HR: Measurement of patient outcome in arthritis. Arthritis Rheum 1980, 23:137-145.

16. Han C, Robinson DW, Hackett MV, Clark P, Fraeman KH, Bala MV: Cardiovascular disease and risk factors in patients with rheumatoid arthritis, psoriatic arthritis, and ankylosing spondylitis. J Rheumatol 2006, 33:2167-2172.

17. Watson DJ, Rhodes T, Guess HA: All-cause mortality and vascular events among patients with rheumatoid arthritis, osteoarthritis, or no arthritis in the UK General Practice Research Database. J Rheumato/ 2003, 30:1196-1202.

18. Turesson C, Jarenros A, Jacobsson L: Increased incidence of cardiovascular disease in patients with rheumatoid arthritis: results from a community based study. Ann Rheum Dis 2004, 63:952-955.

19. Solomon DH, Karlson EW, Rimm EB, Cannuscio CC, Mandl LA, Manson JE, Stampfer MJ, Curhan GC: Cardiovascular morbidity and mortality in women diagnosed with rheumatoid arthritis. Circulation 2003, 107:1303-1307.

20. Wolfe F, Freundlich B, Straus WL: Increase in cardiovascular and cerebrovascular disease prevalence in rheumatoid arthritis. J Rheumatol 2003, 30:36-40.

21. Tunstall-Pedoe $H$, Kuulasmaa $K$, Mähönen $M$, Tolonen $H$, Ruokokoski E, Amouyel P: Contribution of trends in survival and coronary-event rates to changes in coronary heart disease mortality: 10-year results from 37 WHO MONICA project populations. Monitoring trends and determinants in cardiovascular disease. Lancet 1999, 353:1547-1557.

22. Knoops KT, de Groot LC, Kromhout D, Perrin AE, Moreiras-Varela $O$, Menotti A, van Staveren WA: Mediterranean diet, lifestyle factors, and 10-year mortality in elderly European men and women: the HALE project. JAMA 2004, 292:1433-1439.

23. Björnådal L, Brandt $L$, Klareskog $L$, Askling J: Impact of parental history on patients' cardiovascular mortality in rheumatoid arthritis. Ann Rheum Dis 2006, 65:741-745.

24. Manson JE, Greenland P, LaCroix AZ, Stefanick ML, Mouton CP, Oberman A, Perri MG, Sheps DS, Pettinger MB, Siscovick DS: Walking compared with vigorous exercise for the prevention of cardiovascular events in women. N Engl J Med 2002, 347:716-725.

25. Sokka $T$, Häkkinen $A$, Kautiainen $H$, Maillefert JF, Toloza S, Mørk Hansen T, Calvo-Alen J, Oding R, Liveborn M, Huisman M, Alten R, Pohl C, Cutolo M, Immonen K, Woolf A, Murphy E, Sheehy C, Quirke E, Celik S, Yazici Y, Tlustochowicz W, Kapolka D, Skakic V, Rojkovich B, Müller R, Stropuviene S, Andersone D, Drosos AA, Lazovskis J, Pincus T, QUEST-RA Group: Physical inactivity in patients with rheumatoid arthritis: data from twenty-one countries in a cross-sectional, international study. Arthritis Care Res 2008, 59:42-50

26. Liang KP, Liang KV, Matteson EL, McClelland RL, Christianson TJ, Turesson C: Incidence of noncardiac vascular disease in rheumatoid arthritis and relationship to extraarticular disease manifestations. Arthritis Rheum 2006, 54:642-648.

27. Roman MJ, Moeller E, Davis A, Paget SA, Crow MK, Lockshin MD, Sammaritano L, Devereux RB, Schwartz JE, Levine DM, Salmon JE: Preclinical carotid atherosclerosis in patients with rheumatoid arthritis. Ann Intern Med 2006, 144:249-256.

28. Warrington KJ, Kent PD, Frye RL, Lymp JF, Kopecky SL, Goronzy $\mathrm{JJ}$, Weyand CM: Rheumatoid arthritis is an independent risk factor for multi-vessel coronary artery disease: a case control study. Arthritis Res Ther 2005, 7:R984.

29. Dessein PH, Joffe BI, Veller MG, Stevens BA, Tobias M, Reddi K Stanwix AE: Traditional and nontraditional cardiovascular risk factors are associated with atherosclerosis in rheumatoid arthritis. J Rheumato/ 2005, 32:435-442.

30. Goodson NJ, Symmons DP, Scott DG, Bunn D, Lunt M, Silman AJ: Baseline levels of $C$-reactive protein and prediction of death from cardiovascular disease in patients with inflammatory polyarthritis: a ten-year followup study of a primary care-based inception cohort. Arthritis Rheum 2005, 52:2293-2299.

31. Goodson N, Marks J, Lunt M, Symmons D: Cardiovascular admissions and mortality in an incepcion cohort of patients with rheumatoid arthritis with onset in the 1980s and 1990s. Ann Rheum Dis 2005, 64:1595-1601.

32. Bergholm R, Leirisalo-Repo M, Vehkavaara S, Makimattila S, Taskinen MR, Yki-Jarvinen $\mathrm{H}$ : Impaired responsiveness to $\mathrm{NO}$ in newly diagnosed patients with rheumatoid arthritis. Arterioscler Thromb Vasc Biol 2002, 22:1637-1641.

33. Lourida ES, Georgiadis AN, Papavasiliou EC, Papathanasiou AI, Drosos AA, Tselepis AD: Patients with early rheumatoid arthritis exhibit elevated autoantibody titers against mildly oxidized 
LDL and decreased activity of the lipoprotein-associated phospholipase A2. Arthritis Res Ther 2007, 9:R19.

34. Troelsen LN, Garred P, Madsen HO, Jacobsen S: Genetically determined high serum levels of mannose-binding lectin and agalactosyl IgG are associated with ischemic heart disease in rheumatoid arthritis. Arthritis Rheum 2006, 56:21-29.

35. Turesson C, McClelland RL, Christianson TJ, Matteson EL: Severe extra-articular disease manifestations are associated with an increased risk of first ever cardiovascular events in patients with rheumatoid arthritis. Ann Rheum Dis 2007, 66:70-75.

36. Johnsen SP, Larsson H, Tarone RE, McLaughlin JK, Norgard B Friis S, Sorensen HT: Risk of hospitalization for myocardial infarction among users of rofecoxib, celecoxib, and other NSAIDs: a population-based case-control study. Arch Intern Med 2005, 165:978-984.

37. Juni P, Nartey L, Reichenbach S, Sterchi R, Dieppe PA, Egger M: Risk of cardiovascular events and rofecoxib: cumulative metaanalysis. Lancet 2004, 364:2021-2029.

38. Maxwell SR, Moots RJ, Kendall MJ: Corticosteroids: do they damage the cardiovascular system? Postgrad Med J 1994, 70:863-870.

39. Kumeda $Y$, Inaba $M$, Goto $H$, Nagata $M$, Henmi $Y$, Furumitsu $Y$, Ishimura E, Inui K, Yutani Y, Miki T, Shoji T, Nishizawa Y: Increased thickness of the arterial intimamedia detected by ultrasonography in patients with rheumatoid arthritis. Arthritis Rheum 2002, 46:1489-1497.

40. Solomon DH, Avorn J, Katz JN, Weinblatt ME, Setoguchi S, Levin $\mathrm{R}$, Schneeweiss S: Immunosuppressive medications and hospitalization for cardiovascular events in patients with rheumatoid arthritis. Arthritis Rheum 2006, 54:3790-3798.

41. Davis JM, Maradit Kremers H, Crowson CS, Nicola PJ, Ballman KV, Therneau TM, Roger VL, Gabriel SE: Glucocorticoids and cardiovascular events in rheumatoid arthritis: a population-based cohort study. Arthritis Rheum 2007, 56:820-830.

42. Choi HK, Hernan MA, Seeger JD, Robins JM, Wolfe F: Methotrexate and mortality in patients with rheumatoid arthritis: a prospective study. Lancet 2002, 359:1173-1177.

43. Heliovaara M, Aho K, Aromaa A, Knekt $P$, Reunanen A: Smoking and risk of rheumatoid arthritis. J Rheumatol 1993, 20:1830-1835

44. Georgiadis AN, Papavasiliou EC, Lourida ES, Alamanos Y, Kostara C, Tselepis AD, Drosos AA: Atherogenic lipid profile is a feature characteristic of patients with early rheumatoid arthritis: effect of early treatment - a prospective, controlled study. Arthritis Res Ther 2006, 8:R82.

45. Hürlimann D, Forster A Noll G, Enseleit F Chenevard R, Distler O, Béchir M, Spieker LE, Neidhart M, Michel BA, Gay RE, Lüscher TF, Gay S, Ruschitzka F: Anti-tumor necrosis factor-alpha treatment improves endothelial function in patients with rheumatoid arthritis. Circulation 2002, 106:2184-2187.

46. Gonzalez-Juanatey C, Testa A, Garcia-Castelo A, Garcia-Porrua C, Llorca J, Gonzalez-Gay MA: Active but transient improvement of endothelial function in rheumatoid arthritis patients undergoing long-term treatment with anti-tumor necrosis factor alpha antibody. Arthritis Rheum 2004, 51:447-450.

47. Dominguez $H$, Storgaard $H$, Rask-Madsen $C$, Steffen Hermann $T$, Ihlemann N, Baunbjerg Nielsen D, Spohr C, Kober L, Vaag A, TorpPedersen C: Metabolic and vascular effects of tumor necrosis factor-alpha blockade with etanercept in obese patients with type 2 diabetes. J Vasc Res 2005, 42:517-525.

48. Greenberg J, Lin S, Decktor D, Dabbous O, White B, Baumgartner S, Montgomery M, Chi E, Hinkle K, Reed G, Hochberg M, Abramson S, Kremer J: Association of duration of TNF antagonist treatment with reduction in cardiovascular outcomes in RA patients [abstract]. Arthritis Rheum 2006, 54:s422.

49. Dixon WG, Watson KD, Lunt M, Hyrich KL, Silman AJ, Symmons DP: Reduction in the incidence of myocardial infarction in patients with rheumatoid arthritis who respond to anti-tumor necrosis factor alpha therapy: results from the British Society for Rheumatology Biologics Register. Arthritis Rheum 2007, 56:2905-2912.

50. Carmona L, Descalzo MA, Perez-Pampin E, Ruiz-Montesinos D, Erra A, Cobo T, Gómez-Reino JJ: All-cause and cause-specific mortality in rheumatoid arthritis are not greater than expected when treated with tumour necrosis factor antagonists. Ann Rheum Dis 2007, 66:880-885. 